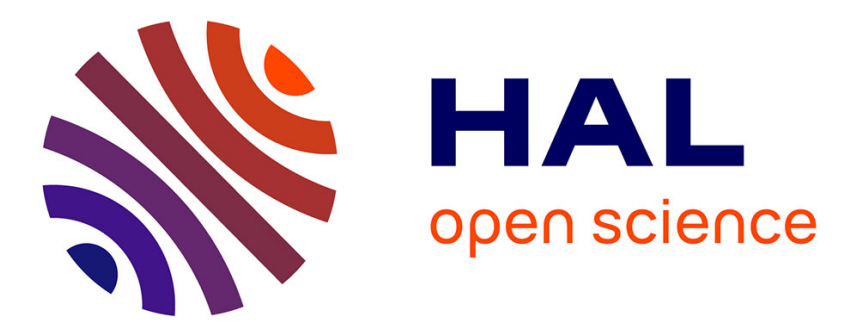

\title{
Exploratory and instantaneous swimming speeds of amphidromous fish school in shallow-water coastal lagoon channels
}

\author{
Patrice Brehmer, Jean Guillard, P. I. C. Pinzon, Pascal Bach
}

\section{To cite this version:}

Patrice Brehmer, Jean Guillard, P. I. C. Pinzon, Pascal Bach. Exploratory and instantaneous swimming speeds of amphidromous fish school in shallow-water coastal lagoon channels. Estuaries and Coasts, 2011, 34 (4), pp.739-744. 10.1007/s12237-011-9409-3 . ird-00607866

\section{HAL Id: ird-00607866 https://hal.ird.fr/ird-00607866}

Submitted on 11 Jul 2011

HAL is a multi-disciplinary open access archive for the deposit and dissemination of scientific research documents, whether they are published or not. The documents may come from teaching and research institutions in France or abroad, or from public or private research centers.
L'archive ouverte pluridisciplinaire HAL, est destinée au dépôt et à la diffusion de documents scientifiques de niveau recherche, publiés ou non, émanant des établissements d'enseignement et de recherche français ou étrangers, des laboratoires publics ou privés. 


\title{
Amphidromous Fish School Exploratory and Instantaneous Swimming Speeds in
}

\author{
Shallow Water Coastal Lagoon Channels
}

\section{Patrice Brehmer • Jean Guillard • Pablo I. Caballero Pinzon • Pascal Bach}

P. Brehmer
Institut de Recherche pour le Développement, UMR6539, BP70, 29280, Plouzané, France (1)

J. Guillard
INRA, UMR CARRTEL, BP 511, 74203, Thonon-les-bains, France (1)
P.I. Caballero Pinzon

Centre de Recherche Halieutique méditerranéenne et tropicale (IRD, Ifremer, Université de Montpellier 2), BP 170, 34203, Sète, France

present adress: Centro de Estudios Tecnológicos del Mar No. 10 (CETMAR Chetumal), 8 Boulevard Bahía s/n, 77010 Chetumal, Quintana Roo, Mexcico 
Abstract Although the estimation of in situ swimming speed of a fish school remains seldom documented, this elementary information is needed concerning gregarious fish species behavioural purposes, ecological and management studies. This study analyses data collected in situ for small pelagic fish schools in two shallow water lagoon channels using multibeam sonar. In horizontal beaming, the high resolution sonar covers the whole cross part of the channels, providing dynamic echo traces of mobile fish schools which permit the gathering of information on them during their passage inside the channels. Two school swimming speed indicators are distinguished: the average of a series of instantaneous speed values (ISS, based on successive measurements) and the exploratory speed (ESS, based on the total observation time). These swimming speeds are estimated for each observed fish school according to their Euclidian position within the sonar beam and the ID ratio defined as the average of ISS values divided by the ESS, is calculated as an indicator of the trajectory of the displacement of the school. The amphidromous fish schools average ISS values per school vary from $0.15 \mathrm{~m} . \mathrm{s}^{-1}$ to a maximum of $4.46 \mathrm{~m} . \mathrm{s}^{-1}$ while on the other hand; ESS per school varies at lower level amplitude from $0.04 \mathrm{~m} . \mathrm{s}^{-1}$ to a maximum of $3.77 \mathrm{~m} . \mathrm{s}^{-1}$. A majority of fish schools exhibit an ID value demonstrating an oriented swimming behaviour through the channel related to the migration process. This trend appears as an intrinsic property of school movements according to the sampling period, while $36 \%$ differ from this general trend. This result comforts the 'multi-transit' hypothesis, as all schools do not show a directional trajectory assumed as representative of active migration behaviour. This result, however, does not allow a quantitative estimation of the part of schools migrating actively (i.e. the migration flow), but it permits a qualitative interpretation of this pattern. However, the sampling design should allow one to obtain a quantitative estimation of the flow. The presentation of this methodology and the continuous improvements multibeam sonar technologies foresee, allow henceforth the measurements of fish school swimming speed in their habitat at a small spatio- 
50 temporal scale, as well as for large individual fish and marine megafauna. Our methodology

51 can be carried out to analyse movement characteristics of large fishes and small schools in

52 their habitat and has a wide range of applications in the scope of behavioural studies in an

53 ecosystemic approach such as for management purposes.

54

55 Keywords: gregarious fish · migration $\cdot$ multi-transit $\cdot$ behaviour $\cdot$ lagoon $\cdot$ sonar.

56

57 


\section{Introduction}

The use of the active underwater acoustics has significantly increased over the course of time, enabling nowadays the study of both single fish and fish school behaviours in various aquatic ecosystems. In lakes, rivers and estuaries, in situ studies (counting, swimming behaviour, geographical distribution in the habitat, circadian behaviour) of both fishes and schools using echosounder, have increased over the past few years (e.g. Gerlotto et al. 1992; Duncan and Kubecka 1996). Moreover, the development of the technology has allowed a shift from descriptive to quantitative studies (e.g. Stieg and Johnston 1996; Gauthier et al. 1997; Maes et al. 1999). Subsequently, due to the use of split-beam sounders in a fixed location, measurements of movement characteristics of both individual fish and schools (swimming speed and trajectory, within horizontal and vertical habitat dimensions) were carried out in situ (e.g. Mulligan and Keiser 1996; Arrhenius et al. 2000; Mulligan and Chen 2000; Guillard and Colon 2000; Cech and Kubecka 2002; Lilja et al. 2003). The swimming speed capabilities could be estimated in controlled conditions using laboratory aquaria (Wardle 1975), video in water tank (Soria et al. 2007), swim tunnel (Lee et al. 2003) or in the aquatic environment using an electronic tag on individual fishes (Fängstam 1993; Dagorn et al. 2006). Electronic tags sometimes affect the swimming performance, particularly on small fish (Stakenas et al. 2009), and in any case are unable to provide information on the whole school movements.

Quantitative results of migrating ichtyofauna between sea and lagoon have been obtained (Miller et al. 1990; Gonzalez and Gerlotto 1998; Bardin and Pont 2002) emphasising the importance of migratory flows between the two ecosystems. Coastal lagoons have a great ecological importance and their functions as nurseries, refuge zones and feeding zones are well recognized (Beck et al. 2001). Previous studies demonstrate that fish school behaviours can be accurately described using multibeam sonar in horizontal beaming (e.g. Misund and 
83

84

Algen 1992; Nøttestad et al. 1996; Onsrud et al. 2005; Brehmer et al. 2006a, b), even in shallow waters (Guillard 1998), because this acoustic device displays a continuous visualization of fish school movements (Pitcher et al. 1996).

In this paper we present in situ observations of fish schools performed at a short range in shallow waters, using multibeam sonar in horizontal beaming in a fixed position. This allows the measurement of fish school swimming speed values at two different temporal scales: for short time periods of the school in the acoustic beam (instantaneous speeds) and the global time of the presence of the school inside the acoustic beam (exploratory speed). From these observations, we discuss the schools' migration behaviour in a lagoon channel and its consequences on the school counting methodology using acoustic remote systems in horizontal beaming and fixed position.

\section{Material and Methods}

\section{The study areas: two Mediterranean shallow water lagoon channels}

Our research takes place within two channels that link coastal lagoons of Ingril (549 ha) and Prévost (380 ha) to the Mediterranean Sea. These two lagoons are part of a series of shallow ponds located along the coastal area of the Hérault area in the south of France $\left(43^{\circ} 44^{\prime} \mathrm{N}\right.$; 03 ${ }^{\circ} 79^{\prime} \mathrm{E}$ and $43^{\circ} 52^{\prime} \mathrm{N} ; 03^{\circ} 90^{\prime} \mathrm{E}$ ). The Ingril channel has a 'bank to bank' width of $25 \mathrm{~m}$ and the Prévost ones $17 \mathrm{~m}$, both having a maximum depth of around $1.5 \mathrm{~m}$ (Brehmer et al. 2006a). Artisanal fisheries in Mediterranean lagoons are considered as an ancient activity dating back to Gallo-Roman times using fishing methods practically unchanged over the course of time (Gourret,1897; Bourquard 1985; Bach 1992). The most abundant species according to landings, in biomass, is the eel (Anguilla anguilla), but other species such as big-scale sand 
smelt (Atherina boyeri), the bass (Dicentrarchus labrax), the gilthead sea bream (Sparus

109 aurata), and various mugilidae (Liza ramada, Liza aurata, Mugil cephalus, Chelon labrosus)

110 are also abundant in captures for seasonal periods (Brehmer et al., 2006a). In this work, only

111 pelagic aggregative species in schools (Pitcher 1984) have been studied: the major species

112 encountered are the bass, the gilthead sea bream and the mullets (Brehmer et al. 2006a). All of

113 these species are known to migrate between the lagoons and the sea, due to their trophic

114 behaviour (from sea to lagoon during the spring) and/or for both physiological and spawning

115 reasons (from lagoon to sea during the autumn). Cast net sampling carried out during acoustic

116 surveys has shown the presence of fish with fork length sizes ranging from a minimum of 52

$117 \mathrm{~mm}$ (Mugilidae juvenile) to a maximum of $169 \mathrm{~mm}$ (D. labrax).

118 Data analysed in this study came from two acoustic sampling surveys of 24 hours each,

119 performed consecutively during the autumnal migration season in September 1999 inside both 120 lagoon channels (Brehmer et al. 2006a).

122 The high resolution multibeam sonar dynamic observations

124 The RESON Seabat 6012 multi-beam sonar used for data acquisition emits on 60 contiguous beams of $1.5^{\circ}$ each. For reception, the efficient horizontal angle is $90^{\circ}$ with a vertical angle of continuously stored on S-VHS videotapes. The sonar characteristics and the environmental 128 parameters determine the threshold of the sonar resolution, in our case $45 \mathrm{~cm}$ (Brehmer et al., 129 2006b). A preliminary study of acoustic data, intended to quantify the migratory fish school 130 flows collected from the school echo traces (Olsen 1969; Scalabrin and Massé 1993; Moreno 131 et al. 2007) counted from acoustic imagery, was accomplished using the same acoustic 132 equipment used in horizontal beaming (Brehmer et al. 2006a). 
133 The S-VHS video recordings are replayed at the laboratory to select the sonar sequences

134 including fish school echo traces (Brehmer et al. 2006b), which correspond to specific 135 detections of homogeneous continuous responses well discriminated on the screen. For both 136 sampling areas, we were able to observe mobile echo traces (Brehmer et al. 2006a) and

137 stationary ones. We then differentiated the dynamic echo traces, characteristic of fish schools

138 detection ( $v s$. fixed bottom echo traces). In this way, each selected series of sonar images

139 corresponding to a detection of a school on which we attribute an individual code were stored

140 in a fish school library (Fig. 1). The echo traces observed within the sonar acoustic beams less

141 than two seconds were removed from the analysis as well as some schools exhibiting

142 particular behaviours (i.e. splitting/merging phenomenon). Finally, we selected and extracted

143 information on 164 fish schools, 41 and 123 observed in the channels of the Ingril lagoon and

144 the Prévost lagoon, respectively.

146 Sonar data processing of fish school echo traces

148 Each separate fish school data is extracted from the sonar images using the 'Infobancs'

149 software (Brehmer et al. 2006c). For each fish school we obtain the number of consecutive 150 echo traces ' $\mathrm{N}$ ', the total time of observation of echo traces within the beam (in seconds) and 151 the Euclidian position ( $\mathrm{x} ; \mathrm{y}$ ) of the centre of the fish school, defined as the centre of gravity of 152 the surface defining the detected biological structure. From this information and the scale 153 factor of observations on the screen (Brehmer et al. 2006b) we calculate the Instantaneous

154 Swimming Speed values of the fish school, (ISS in $\mathrm{m} . \mathrm{s}^{-1}$ ), outlined on the basis of the 155 difference between two successive positions of the geometric centre of the fish school divided 156 by the time interval between observations. Moreover, we estimate the Exploratory Swimming 157 Speed (ESS in $\mathrm{m}^{-1}{ }^{-1}$ ) outlined on the basis of the rectilinear distance between the first and the 
158 last positions of the fish school divided by the time interval separating these two observations.

159 From this data, we calculated: the mean of ISS values for each school (ISSm), and the

160 indicator of the trajectory of the displacement ID defined as the ratio between ISSm and ESS.

161 The ID index is derived from the 'IHM' Index of Horizontal Movement (Misund, 1991;

162 Brehmer et al. 2006). It is used as an indicator of the horizontal school displacement: above

1630.9 we assume the displacement as straightforward and the lower the ID is, the higher is the

164 sinuosity of the displacement (Epstein, 1989). Non parametric tests and Pearson's correlation

165 analysis between indices were performed with the Statistica software

166 (http://www.statsoft.com/).

168 Results

170 For the 164 fish schools analysed the number of consecutive echo trace observations per

171 school varied from three to eight sonar images. The total of echo traces sampled reaches 621 ,

172 of which 174 and 447 concern schools detected in Ingril and Prévost lagoon channels, 173 respectively. The number of observations for each school varies from 3 to 8 around a mean of

1744 for both lagoons (Table 1). The time of the school presence in the acoustic beam varies from $1752 \mathrm{~s}$ to $31 \mathrm{~s}$ around an average of $10 \mathrm{~s}$ for Ingril and from $2 \mathrm{~s}$ to $34 \mathrm{~s}$ around an average of $10 \mathrm{~s}$ 176 for Prévost (Tab. 1). The distance travelled by a school across the acoustic beam varies from 1 $177 \mathrm{~m}$ to $27.9 \mathrm{~m}$ around an average of $10 \mathrm{~m}$ for Ingril and from $2.2 \mathrm{~m}$ to $50.8 \mathrm{~m}$ around an average 178 of 12.2 for Prévost (Table 1). The relationship between the distance travelled by a school and 179 the residence time of this school in the acoustic beam shows a logarithmic shape for both 180 lagoons (Pearson's correlation coefficient $\mathrm{R}=0.55, \mathrm{p}<0.001$ for Ingril and $\mathrm{R}=0.64, \mathrm{p}$ $181<0.001$ for Prévost) (Fig. 2). 
183

184

185

186

187

188

189

190

191

192

193

194

195

196

197

198

199

200

201

202

203

204

205

Discussion

Fish school swimming speed

The mean of ISS values (ISSm) ranged between $0.15 \mathrm{~m} \cdot \mathrm{s}^{-1}$ and $2.93 \mathrm{~m} \cdot \mathrm{s}^{-1}$ around an average value of $1.31 \mathrm{~m} . \mathrm{s}^{-1}(\mathrm{SD}=0.77)$ in the Ingril channel. For the Prévost lagoon, ISSm ranged between $0.31 \mathrm{~m} \cdot \mathrm{s}^{-1}$ and $4.46 \mathrm{~m} \cdot \mathrm{s}^{-1}$ around an average value $1.51 \mathrm{~m} \cdot \mathrm{s}^{-1}(\mathrm{SD}=0.86)$ (Table 1). The ESS varied between $0.04 \mathrm{~m} . \mathrm{s}^{-1}$ and $2.72 \mathrm{~m} . \mathrm{s}^{-1}$ around a mean value of $1.19 \mathrm{~m} . \mathrm{s}^{-1}(\mathrm{SD}=$ 0.77) for the Ingril channel. It ranged from $0.23 \mathrm{~m} . \mathrm{s}^{-1}$ to $3.77 \mathrm{~m} . \mathrm{s}^{-1}$ with an average of 1.34 $\mathrm{m} . \mathrm{s}^{-1}(\mathrm{SD}=0.79)$ for the Prévost lagoon (Table 1$)$. The scatter plot of ESS values versus ISSm values shows that the major part of observations are distributed along the 1:1 line (i.e. $\mathrm{x}$ $=y$ ), indeed the trend lines for both lagoons were close to it (Fig. 3).

Characteristics of the displacement

The index ID differs between 0.12 and 1.17 around an average value of $0.9(\mathrm{SD}=0.77)$ for Ingril channel. It ranged from 0.31 to 1.25 around an average of $0.89(\mathrm{SD}=0.86)$ for the Ingril lagoon channel (Table 1). As suggested by the Figure 3, for a majority of schools the ID value is equal or close to 1 . Then, $36 \%$ of schools display displacements (ID value below 0.9) which differ with the general trend (Fig. 4). We could envisage that this characteristic would depend on the distance travelled by the school or the time of the observation of the school as ISSm and ESS are correlated. However, this general trend of displacement of schools in both channels was observed whatever the distance travelled (Fig. 5). 
The amplitude of variation of the observation time (Fig. 2) between fish schools came from the loss of detection due to (i) swimming behaviour (i.e. the fish school trajectories can cross the acoustic beams in different manners: horizontally, vertically or slantwise), and (ii) bottom or surface reverberations during the passage of schools within sonar beams which prevent any clear discrimination. The fish school ISSm and ESS calculations were obtained for a minimal number of three observations of the school in the acoustic beam, set on a timing interval which should be defined according to the target speed and the sonar performances (range and pulse length). In our case study, the selected time interval was set at one second for the shortest observation, without restriction in the total time of observation above three seconds (Fig. 2). Within this first investigation, we decided to keep all available information relative to the whole set of digitized sonar sequences selected for each fish school.

Our study demonstrates the ability to estimate the average instantaneous speed (ISSm) in situ of fish schools, which differ in the channels between 0.15 to $4.46 \mathrm{~m} . \mathrm{s}^{-1}$. However the ESS varies between $0.04 \mathrm{~m} . \mathrm{s}^{-1}$ and $3.77 \mathrm{~m} . \mathrm{s}^{-1}$. Such an extent of values could be due to the length of individuals inside the school and an appropriate approach to interpret speed values would be to consider the speed value relative to the length. Unfortunately, we could not translate these swimming speeds into body length per second 'B1.s ${ }^{-1}$, (Bainbridge 1958), as the specific identification from the echo trace was not feasible and because the size of the individual fish within the school could be suspected to be not directly correlated to the fish school swimming speed; obviously inferior to the one of an isolated fish (i.e. not in school) of a same size. Nevertheless we can notice that the maximum value observed could not be related to juvenile fish, as those caught during the experiment. Indeed Wardle (1975) found on individual fish in laboratory aquaria that small fish $(0.1 \mathrm{~m})$ can reach $25 \mathrm{Bl} . \mathrm{s}^{-1}$, while for the smaller fish of 52 $\mathrm{mm}$ sampled in this study the maximum speed value observed of $4.46 \mathrm{~m} . \mathrm{s}^{-1}$ would be converted in $85 \mathrm{Bl} . \mathrm{s}^{-1}$ which is biologically unreliable. For the bigger fish of $169 \mathrm{~mm}$ sampled 
232 by fishing, this maximum speed value would be converted in $26 \mathrm{Bl} . \mathrm{s}^{-1}$ which is biologically 233 reliable. ISSm values can be clustered in four groups (Fig. 6), with a constant swimming 234 speed interval of $1.25 \mathrm{~m} . \mathrm{s}^{-1}$ except for the highest values, which were only observed in the 235 Prevost lagoon. This assumption of a fish group discrimination makes sense according to 236 biological reliable swimming speeds expressed in $\mathrm{Bl}^{-1} \mathrm{~s}^{-1}$ and unpublished data showing a 237 higher value of individual TS on isolated fish (the TS is related to relative individual fish size 238 (Guillard et al. 2004)) from Prévost lagoon (Brehmer 2002, unpublished data); we could 239 assume that would be the same for gregarious fish as the species diversity remains the same 240 between both lagoons (Mouillot et al. 2005). Indeed, the first group could be related to 241 juveniles of mugilidae (< Lf $7.5 \mathrm{~cm}$ ), the second group to $S$. aurata $(\mathrm{Lf} \sim 13 \mathrm{~cm})$, the third 242 group to D. labrax (Lf $\sim 20 \mathrm{~cm}$ ) and the last group which is only present in Prevost (the 243 deeper lagoon vs. Ingril) to adults of D. labrax, S. aurata or from the Mugilidae group.

244 The swimming behaviour is quite variable, even on small spatial and temporal scales, as 245 demonstrated in our analysis. Future study should explore more precisely the fish school 246 kinematic using adapted analysis (e.g. Benhamou 2004; 2006) on larger time scales (i.e. 247 several hours) obtained from different sampling protocols (e.g. mobile transducer along the 248 channel to track the school). The maximum time of observation recorded during this study of $24934 \mathrm{~s}$ does not permit achieving this goal.

250 The multi-transit hypothesis assumes that the same fish school can be recorded several times 251 by the sonar system according to its swimming behaviour (Brehmer et al. 2006a). Cronkite et 252 al. (2007) confirm the multi-transit hypothesis with a study led on a river using split beam 253 echosounder data on individual fish. If we assume that the oriented swimming behaviour 254 corresponds to a certain form of an active migration (continuous swimming activity), 255 considering an ID value above 0.9 as an indicator of this oriented swimming behaviour, our 256 results allow us to estimate that $64 \%$ (Fig. 4) of fish schools exhibit an active migration 
257

258

movement through the channel. Then, this active migration movement appears as an intrinsic property of observed school during our study, as such a general trend of displacement of schools in both channels was observed whatever the distance travelled (Fig. 5). This estimation is reliable under the hypothesis that schools exhibit this swimming behaviour all along their transfer inside the lagoon channel during the well known autumnal migration period of mugilidae, sparidae and centrarchidae fishes. Fish schools not having a well defined migration behaviour regarding their ID value are susceptible to be detected several times in the acoustic beam. They reach $36 \%$ of fish schools which could represent resident fish in lagoons or migratory fish which present rather an exploratory behaviour than a migratory one. The swimming speed of fish schools is an elementary indicator which has an interest in many aspects of the ecology of aggregative fish species (e.g. Gillanders et al. 2003). To gather our data the operating system carried out was time consuming (Fig. 1; video sequences selection and fish school identification, then, sonar image digitization, import of digitized sequences through a software solution and configuration) and an automation of working sequences through a post process of sonar data using dedicated software is in progress. However, these operations need further developments. Indeed, analysed echo traces are easily identifiable, allowing developing a discrimination algorithm of useful echoes to be validated in a second step by an expert (Weill et al. 1993; Brehmer et al. 2006a). The development of both acoustic technologies and data analysing process might be allow to quantify behavioural pattern of fishes at small scale. Consequently, impacts of both fishing and management activities (e.g. shallow water stock assessment as well as marine protected areas, artificial reefs) would be evaluated more accurately. 
282 The multibeam sonar in horizontal beaming allows an analysis of fish school displacement, at

283 short range in shallow water and allows their swimming speed measurements which are 284 precious sources of elementary information for ecological studies or landscaping of shallow 285 water surroundings. In the way of an ecosystemic approach (Garcia et al. 2003; Misund and 286 Skjoldal 2005; Cury and Christensen 2005), the control and the management of the ecological 287 quality of such ecosystems as well as their fisheries components (Sherman and Duda 1999), 288 our methodologies permit to consider free fish school swimming speeds. This elementary 289 information enhances our knowledge of fish school displacement and migration processes 290 which are essential to better our understanding of ecosystem functioning (Gillanders et al. 2912003 ) and finally, to formulate management measures of the seashore. Our methodology can 292 be extended to other fish target types in aquatic ecosystems, such as large isolated fish in the 293 open ocean (elasmobranchii, marine mammals) obviously subject to the reverberation of the 294 focused target (i.e. above the required threshold and resolution). The development of the 295 acoustic methodology should lead to numerous in situ measures in aquatic ecosystems, such 296 as on large marine animals swimming behaviour in their natural habitat, or within ecological 297 and anthropogenic perturbation situations (e.g. habitat eutrophication). The swimming speed 298 should be used to propose indicators to discriminate fish school species or characterise their 299 behavioural motivation (feeding, spawning, and migration). Lastly the morphological 300 characteristics of the fish school (shape, surface, size of individual fish) can be related to the 301 swimming speed measurements in order to improve our understanding of aggregative fish 302 displacement.

304 Acknowledgements This work has been supported by a state-regional grant 'CPER XI' and 305 the GIS Europole Mer. We are grateful to Thang Do Chi (CNRS, UMR Ecolag), Marc Soria, 
306 François Gerlotto and Laurence Vicens (IRD, UMR Eme) for their help during the project and 307 all the participants of the field missions.

\section{References}

Arrhenius, F., B.J. Benneheij, L.G. Rudstam, and D. Boisclair. 2000. Can stationary bottom split-beam hydroacoustics be used to measure fish swimming speed in situ? Fisheries Reseach 45: 31-41.

Bach, P., P. Legendre, M. Amanieu, and G. Lasserre. 1992. Strategy of eel (Anguilla anguilla, L.) exploitation in the Thau lagoon. Estuarine, Coastal and Shelf Science 35: 55-73.

Bainbridge, R. 1958. The Speed of Swimming of Fish as Related to Size and to the Frequency and Amplitude of the Tail Beat. Journal of experimental Biolology 35: 109-133.

Bardin, O., and D. Pont. 2002. Environmental factors controlling the spring immigration of two estuarine fishes (Atherina boyeri and Pomatoschistus spp.) into a Mediterranean lagoon. Journal of Fish Biology 61: 560-578.

Beck, M.W., K.L. Heck, K.W. Able, D.L. Childers, D.B. Eggleston, B.M. Gillanders, B. Halpern, C.G. Hays, K. Hoshino, T.J. Minello, R.J. Orth, P.F. Sheridan, and M.P. Weinstein 2001. The identification, conservation, and management of estuarine and marine nurseries for fish and invertebrates. BioScience 51: 633-641.

Benhamou, S. 2004. How to reliably estimate the tortuosity of an animal's path: straightness, sinuosity, or fractal dimension? Journal of Theoretical Biology 229: 209-220.

Benhamou, S. 2006. Detecting an orientation component in animal paths when the preferred direction is individual-dependent. Ecology 87: 518-528. 
Bourquard, C., 1985. Structure et mécanisme de mise en place, de maintien et d'évolution des peuplements ichthyologiques lagunaires du Golfe du Lion. Thèse de doctorat à l’Université Montpellier II, 337 pp.

Brehmer, P., 2002. Flux migratoire d'automne des poissons pélagiques amphidromes sur trois graus languedociens. Rapport IRD, Fdi 010027353, CRHMT, Sète, 82 p.

Brehmer, P., D. Mouillot, and T. Do Chi. 2006a. Amphidromus fish school diel flow in two Mediterranean lagoons by combining sonar and fishing data. Journal of Experimental Marine Biology and Ecology 334(1): 139-150.

Brehmer, P., C. Vercelli, F. Gerlotto, F. Sanguinède, Y. Pichot, D. Buestel, and Y. Guénnegan. 2006b. Multibeam sonar three-dimensional monitoring of mussel culture grounds in open sea for management purpose. Aquaculture 252 (2-4): 234-241.

Brehmer, P., T. Lafont, S. Georgakarakos, E. Josse, F. Gerlotto, and C. Collet. 2006c. Omnidirectional multibeam sonar monitoring: Applications in fisheries science. Fish and Fisheries 7: 165-179.

Cech, M., and J. Kubecka. 2002. Sinusoïdal cycling swimming pattern of reservoir fishes. Journal of Fish Biology 61: 456-471.

Cronkite, G., T. Mulligan, J. Holmes, and H. Enzenhofer. 2007. Categorising salmon migration behaviour using characteristics of split-beam acoustic data. Aquatic Living Resources 20: 205-212.

Cury, P.M., and V. Christensen. 2005. Quantitative ecosystem indicators for fisheries management. ICES Journal of Marine Science 62: 307-310.

Duncan, A., and J. Kubecka. 1996. Patchiness of longitudinal fish distributions in a river as revealed by a continuous hydroacoustic survey. ICES Journal of Marine Science 53: 161-166. 
Epstein, N. 1989. On tortuosity and the tortuosity factor in flow and diffusion through porous media. Chemical engineering science 44(3): 777- 779.

Fängstam, H. 1993. Individual downstream swimming speed during the natural smolting period among young of Baltic salmon (Salmo salar). Canadian Journal of Zoology 71: 1782-1786.

Garcia, S.M., A. Zerbi, C. Aliaume, T. Do Chi, and G. Lasserre. 2003. The ecosystem approach to fisheries: issues, terminology, principles, institutional foundations, implementation and outlook. FAO Fisheries Technical Paper 443, 71 pp.

Gauthier S., D. Boisinclair, and P. Legendre. 1997. Evaluation of a variable angle scanning method to estimate relative abundance and distribution of fish using a single-beam echosounder in shallow lakes. Journal of Fish Biology 50: 208-221.

Gerlotto, F., R. Claro, C. Hernandez-Corujo, and J.P. Garcia Artega. 1992. Una metodologia para la evaluacion de los recursos pesqueros por hidroacustica en aguas someras. Scientia Marina 58: 309-319.

Gillanders, B.M., K.W. Able, J.A. Brown, D.B. Eggleston, and P.F. Sheridan. 2003. Evidence of connectivity between juvenile and adult habitats for mobile marine fauna: an important component of nurseries. Marine Ecological Progress Series 247: 281-295.

Gonzalez, L., and F. Gerlotto. 1998. Observation of fish migration between the sea and a mediterranean lagoon (Etang de l'Or, France) using multibeam sonar and split beam echo sounder. Fisheries Research 34(1-2): 15-22.

Gourret, P. 1897. Les étangs saumâtres du Midi de la France et leurs pêcheries. Annales du Museum d'Histoire Naturelle de Marseille 5: 1-386.

Guillard, J. 1998. Daily migration cycles of fish populations in a tropical estuary (SineSaloum, Senegal) using a horizontal-directed split-beam transducer and multibeam sonar. Fisheries Research 35: 21-29. 
378 Guillard, J., and M. Colon. 2000. First results on migrating shad (Alosa fallax) and mullet (Mugil cephalus) echocounting in a lock on the Rhône River (France) using a splitbeam sounder, and relationships with environmental data and fish caught. Aquatic Living Resources 13: 327-330.

Guillard, J., A. Lebourges-Dhaussy, and P. Brehmer. 2004. Simultaneous Sv and TS measurements on Young-of-the-Year (YOY) freshwater fish using three frequencies. ICES Journal of Marine Science, 61: 267-273.

Lee, C.G., A.P. Farrell, A.G. Lotto, M.J. MacNutt, S.G. Hinch, and M.C. Healey. 2003. The effect of temperature on swimming performance and oxygen consumption in adult sockeye (Oncorhynchus nerka) and coho (O. kisutch) salmon stocks. Journal of Experimental Biology 206: 3239-3251.

Lilja, J., T. Keskinen, J. Marjomäki, P. Valkeajärvi, and J. Karjalainen. 2003. Upstream migration activity of cyprinids and percids in a channel, monitored by a horizontal split-beam echosounder. Aquatic Living Resources 16: 185-190.

Maes, J., Pas, J., Taillieu, A., Van Damme, P.A., and F.P. Ollevier. 1999. Diel changes in the vertical distribution of juvenile fish in the Zeeschelde Estuary. Journal of Fish Biology 54: 1329-1333.

Miller, J.M., Pietrafesa, L.J., and N.P. Smith. 1990. Principles of hydraulic management of coastal lagoons for aquaculture and fisheries. FAO Fisheries Technical Paper 314, Rome, FAO. 88 pp.

Misund, O.A. 1991. Swimming Behaviour of Schools Related to Fish Capture and Acoustic Abundance Estimation. PhD Thesis. University of Bergen, Bergen, 132 pp.

Misund, O.A., and A. Algen., 1992. Swimming behavior of fish schools in the North Sea during acoustic surveying and pelagic trawl sampling. ICES Journal of Marine Science 49: 325-334. 
403

404

405

406

407

408

409

410

411

412

413

414

415

416

417

Misund, O.A., and H.R. Skjoldal. 2005. Implementing the ecosystem approach: experiences from the North Sea, ICES, and the Institute of Marine Research, Norway. Marine Ecological Progress Series 300: 260-265.

Mouillot, D., J. Laune, J.A. Tomasini, C. Aliaume, P. Brehmer, E. Dutrieux, and T. Do Chi. 2005. Assessment of coastal lagoon quality with taxonomic diversity indices of fish, zoobenthos and macrophyte communities. Hydrobiologia 550: 1-10.

Moreno, G., E. Josse, P. Brehmer, and L. Nøttestad. 2007. Echotrace classification and spatial distribution of pelagic fish aggregations around drifting fish aggregating devices (DFAD). Aquatic Living Resources 20: 343-356.

Mulligan, T.J., and R. Kieser. 1996. A split-beam echo counting model for riverine use. ICES Journal of Marine Science 53: 403-406.

Mulligan, T.J., and D.G. Chen. 2000. Comment on 'Can stationary bottom split-beam hydroacoustics be used to measure fish swimming speed in situ?' by Arrhenius et al. Fisheries Research 49: 93-96.

Nøttestad, L., M. Aksland, A. Beltestad, A. Fernoe, A. Johannessen, and O.A. Misund. 1996. Schooling dynamics of Norwegian spring spawning herring (Clupea harengus L.) in a coastal spawning area. Sarasia 80(4): 277-284.

Pitcher, J.T. 1984. Behaviour of teleost fishes. Chapman et Hall Londres, Fish and Fisheries, Series 7, $715 \mathrm{pp}$.

Olsen, K. 1969. A note on estimating school size from echotraces. FAO Fish. Rep. 78: 37-48.

Onsrud, M.S.R., S. Kaartvedt, and M.T. Breien. 2005. In situ swimming speed and swimming behaviour of fish feeding on the krill Meganyctiphanes norvegica. Canadian Journal of Fisheries and Aquatic Sciences 62(8): 1822-1832. 
426 Pitcher, T.J., O.A. Misund, A. Fernö, B. Totland, V. Melle. 1996. Adaptive behaviour of herring schools in the Norwegian Sea as revealed by high-resolution sonar. ICES Journal of Marine Science 53: 449-452.

Scalabrin, C., and J. Massé. 1993. Acoustic detection of the spatial and temporal distribution of fish shoals in the Bay of Biscay. Aquatic Living Resources 6: 269-283.

Sherman, K., and A.M. Duda. 1999. An ecosystem approach to global assessment and management of coastal waters. Marine Ecological Progress Series 190: 271-287.

Soria, M., P. Fréon, and P. Chabanet. 2007. Schooling properties of an obligate and a facultative fish species. Journal of Fish Biology 71: 1257-1269.

Stakenas, S., G.H. Copp and D.M. Scott. 2009. Tagging effects on three non-native fish species in England (Lepomis gibbosus, Pseudorasbora parva, Sander lucioperca) and of native Salmo trutta. Ecology of Freshwater Fish 18: 167-176.

Steig, T.W., and S.V. Johnston. 1996. Monitoring fish movement patterns in a reservoir using horizontally scanning split-beam techniques. ICES Journal of Marine Science 53(2): $435-441$.

441 Wardle, C.S. 1975. Limit of fish swimming speed. Nature 255: 725-727. 


\section{Table 1}

445 Summary of school swimming speeds (ESS: Exploration Swimming Speed. ISS:

446 Instantaneous Swimming Speed) descriptors values per lagoon (Ingril and Prévost), with their

447 total time and ' $N$ ' number of observations, their distance travelled across the beams and their 448 ratio ID (i.e. average ISS divided by the ESS).

449

\begin{tabular}{|c|c|c|c|c|c|c|c|}
\hline Lagoon & & $\begin{array}{c}\text { Total time } \\
\text { (s) }\end{array}$ & $\mathrm{N}$ & $\begin{array}{c}\text { ESS } \\
\left(\mathrm{m} \cdot \mathrm{s}^{-1}\right)\end{array}$ & $\begin{array}{l}\text { ISSm } \\
\left(\mathrm{m} . \mathrm{s}^{-1}\right)\end{array}$ & $\begin{array}{c}\text { Distance } \\
(\mathrm{m})\end{array}$ & ID \\
\hline \multirow{3}{*}{ Ingril } & Mean & 10 & 4 & 1,19 & 1,31 & 10 & 0,89 \\
\hline & Max. & 31 & 8 & 2,72 & 2,93 & 27,9 & 1,25 \\
\hline & Min. & 2 & 3 & 0,05 & 0,15 & 1,1 & 0,31 \\
\hline \multirow{3}{*}{ Prévost } & Mean & 10 & 4 & 1,34 & 1,51 & 12,6 & 0,9 \\
\hline & Max. & 34 & 8 & 3,77 & 4,46 & 50,8 & 1,17 \\
\hline & Min. & 2 & 3 & 0,23 & 0,31 & 2,2 & 0,12 \\
\hline
\end{tabular}

450 
452 Fig. 1 Scheme representing the sonar data collection, their treatment, which include several 453 steps (selection of sonar sequence, digitalization, identification of echo traces on sonar 454 images, data extraction and then exportation for final analysis on ad hoc software), and their 455 analysis to obtain the swimming speed measurements.

Fig. 2 The relationship between the school observation time and the distance travelled inside the sonar beams (grey triangle, doted line: Ingril lagoon; black empty circle, full line: Prévost lagoon) shown a logarithmic shape, higher for the Prévost values than the Ingril ones.

Fig. 3 The relationship between the 'ISSm' and the 'ESS' (grey triangle: Ingril lagoon; black empty circle, Prévost lagoon) shown a linear shape (grey line $\mathrm{y}=\mathrm{x}$. Ingril trend line black doted $y=0.916 x ; R^{2}=0.87$. Prévost trend line full black $y=0.872 x ; R^{2}=0.83$ ) which were comparable for both lagoons.

Fig. 4 Cumulative frequency of the fish school ID defined as the average of instantaneous swimming speed 'ISS' dived by the exploration swimming speed 'ESS'. The schools having an ID below 0.9 represent $36 \%$ of the total.

Fig. 5 Relationship between the distance travelled inside the beams by the fish school and the

471 ID (grey triangle: Ingril lagoon; black empty circle, Prévost lagoon). The ID values appear as 472 not linked to the distance travelled.

474 Fig. 6 Histogram of average of instantaneous swimming speed of the fish schools from the 475 Prevost (black) and Ingril (grey) lagoons, where 4 groups can be distinguished at a regular 476 swimming speed interval $\left(1.25 \mathrm{~m} \cdot \mathrm{s}^{-1}\right)$. 